\title{
The Low-cost fare response to new entry
}

\author{
Paolo Malighetti $\cdot$ Paleari Stefano $\cdot$ Renato Redondi
}

Received: 12 December 2012 / Accepted: 6 March 2013 /Published online: 5 April 2013

(C) The Author(s) 2013. This article is published with open access at SpringerLink.com

\begin{abstract}
Purpose This study analyzes easyJet's fare response to new entry. Traditionally, this stream of literature has focused on the reactions of network carriers to competition from lowcost carriers. As low-cost services spread, however, the number of low-cost incumbents is rising. This paper aims to shed light 16 on low-cost price behaviour in the European context.

Method The analysis is based on an original dataset composed of all fares offered by easyJet up to 90 days beforedeparture, on all flights during the period 20072009. We focus on short-term price reactions by employing the event study methodology. We decompose the price response into three terms: the average fare, dynamic pricing, and fare dispersion around the predicted price curve.

Results Our results show that easyJet's temporal price discrimination tends to decrease after a new entry, especially when the new entrant is a traditional carrier. There is also some evidence for an average fare reduction of about $3 \%$.
\end{abstract}

Keywords Low-cost incumbent $\cdot$ EasyJet $\cdot$ Fare response

\footnotetext{
P. Malighetti $(\square) \cdot$ P. Stefano

Department of Economics and Technology Management,

University of Bergamo, Viale G. Marconi 5,

24044, Dalmine, Bergamo, Italy

e-mail: paolo.malighetti@unibg.it

P. Stefano

e-mail: stefano.paleari@unibg.it

R. Redondi

Department of Mechanical Engineering,

University of Brescia, Viale Branze 38,

25123, Brescia, Italy

e-mail: renato.redondi@unibs.it
}

\section{Introduction}

In recent years, the market share of low cost-carriers (LCCs) has increased in most of the world's short-haul markets. LCCs have grown both by serving secondary airports and by entering the markets of full-service carriers (FSCs). Thus, traditional research has focused on the reactions of FSCs to LCC entrants.

LCCs are currently growing much more rapidly than other types of carriers. If this trend does not change dramatically, LCCs will soon dominate most short-haul markets. Figure 1 shows the share of departing flights offered by LCCs in some major European markets. In Spain and the UK, their share is already about $40 \%$. LCCs are expected to carry about $50 \%$ of short-haul passengers in Europe by 2015 [1].

Table 1 reports the growth of the three major European LCCs on competitive routes. As low-cost services saturate the market, the number of new routes with enough demand to merit adding a new service decreases. Likewise, the fraction of routes with competitors is increasing for all three carriers.

The attitude of LCC incumbents towards FSCs and new LCCs is expected to assume greater relevance in the near future. The data collected for this study show that new entry is already occurring on traditional LCC routes. During the period 2007-2009, we found about 200 new entries on routes already served by easyJet (see section 3 for details).

How do LCCs react to new entry? This work contributes to our understanding of LCC responses by analysing changes in the short-run fares offered by easyJet in response to new entries during 2007-2009. We analyze the fare response in three dimensions: the average fare offered up to 90 days before departure, the dynamic pricing intensity, and the price dispersion, the latter defined as the daily adjustments relative to the predicted temporal fare curve. 


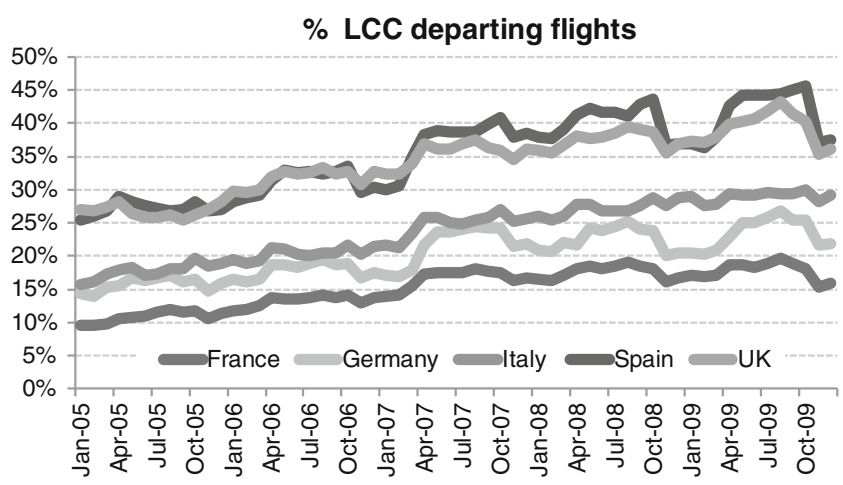

Fig. 1 Growth of low-cost market share. Source: the authors' analysis of Eurocontrol data

\section{Literature review}

The paper builds on the literature referring to airline pricing strategies and competition, especially works dealing with the fare response to new entries.

The literature has shown that when LCCs enter a market, the average fare on the route decreases [2,3]. However, results are mixed with respect to the strength of the reaction. Ito and Lee [4] find little evidence that FSCs employ entry deterrence strategies. In the Australasian market, Forsyth [5] observed no significant adaption of FSC strategies to the new market pattern. Among intra-European routes departing from Italy, Alderighi et al. [6] find that FSCs reacted to low-cost entries by reducing fares in all classes proportionally. Morrison and Winston [7] find that fares increased when a low-cost carrier (either Southwest or America West) dropped a route. Goolsbee and Syverson [8] show that FCSs on the U.S. market pre-emptively reduce fares in reaction to an increased threat of Southwest's entry. Daraban and Fournier [9] analyzed the timing of FCS fare reactions and the interdependence of fares from adjacent airline routes. They find evidence of spatial correlation between fares, confirming the existence of "indirect competition effects". Their research also shows that the FCSs anticipate part of the fare reduction, although most of the pro-competitive effects take place after entry.

The effects of new entry on price dispersion are even more difficult to analyse. In a seminal paper, Borenstein and Rose [10] find that routes with higher levels of competition are characterized by a greater degree of price dispersion. Gerardi and Shapiro [11], on the other hand, find that dispersion decreases with the level of competition. They also make the theoretical argument that dispersion depends on the ability of airlines to mark up fares and/or pricediscriminate. ${ }^{1}$ They argue that when new carriers enter a market, increased competition restricts these strategies and

\footnotetext{
${ }^{1}$ Price discrimination requires that the customers have a range of demand elasticities, and that the carrier has some way of distinguishing between customer types.
}

Table 1 Growth of low-cost carrier networks on competitive routes. Source ICCSAI Factbook $(2007,2008,2009)$

\begin{tabular}{|c|c|c|c|c|c|c|}
\hline \multirow[t]{2}{*}{ Year } & \multicolumn{3}{|c|}{$\begin{array}{l}\text { Overall no. of routes with } \\
\text { competitors }\end{array}$} & \multicolumn{3}{|c|}{$\%$ of routes with competitors } \\
\hline & Ryanair & easyJet & $\begin{array}{l}\text { Air } \\
\text { Berlin }\end{array}$ & Ryanair & easyJet & $\begin{array}{l}\text { Air } \\
\text { Berlin }\end{array}$ \\
\hline 2009 & 248 & 381 & 526 & $13.1 \%$ & $51.8 \%$ & $58.3 \%$ \\
\hline 2008 & 213 & 372 & 452 & $13.9 \%$ & $53.3 \%$ & $52.6 \%$ \\
\hline 2007 & 86 & 201 & 515 & $8.9 \%$ & $40.4 \%$ & $63.6 \%$ \\
\hline 2006 & 54 & 129 & 350 & $8.4 \%$ & $30.7 \%$ & $67.8 \%$ \\
\hline
\end{tabular}

therefore the dispersion should decrease. An alternative theory predicts that price dispersion actually derives from incumbent brand loyalty: new entrants try to attract priceconscious customers by offering lower prices, but this strategy has little effect on the existing base of high-paying customers (with frequent flyer programmes). In this scenario, a positive relationship exists between price dispersion and competitive intensity. Martin \& Koo [12], in their analysis of daily fares offered on 1,000 U.S. domestic routes, find that price dispersion is positively influenced by the presence of low-cost carriers but not by the intensity of competition. Dana [13] shows that if individual and aggregate demand are uncertain price dispersion may characterise pricing strategies of firms even if they have no market power.

Given that these and other questions on the behaviour of FCSs are still open, it should not be surprising that we know very little about the response of incumbent LCCs to new entries. This work analyses entry scenarios where the incumbent is a low-cost carrier rather than a FCS, in the context of the European market. We anticipate that because LCCs and FSCs employ different business models and pricing strategies, the two types of carriers may react differently to new entries.

Compared with traditional airlines revenue management ([14-16]) LCCs typically employ a simpler dynamic pricing structure. Their policy is to offer all customers the same price, which tends to increase as the departure day approaches. LCCs also normally set a very low price on early bookings in order to exploit latent demand.

A review of temporal fare curves observed in the airline industry can be found in Button and Vega [17]. Koenigsberg et al. [18] analyse the pricing strategies of easyJet on 23 flights, and derive the conditions (capacity, duration of tickets offered) under which a strategy of not offering lastminute deals is preferable. Malighetti et al. [19] employ the family of fare curves presented by Anjos [20] to analyse the pricing structure of Ryanair. Malighetti et al. [19] and Piga and Bachis [21] both note that fares are not strictly monotonic with time. Piga and Bachis [21] found that the 2 weeks prior to departure have more volatile prices than other 
periods, and suggest that this effect is a consequence of price adjustments following the airline's improved understanding of the flight's load factor.

Most theoretical and empirical studies of low-cost airlines focus on the relationship between pricing and route characteristics, market structure, and other variables $([19,22-25]$. The diversity of these and other results suggests that the effects of competition on low-cost carrier pricing are complex and not easily predictable. Pels and Rietveld analyse the London-Paris market, on which both low-cost and traditional carriers operate. Some of these carriers seem to lower fares when potential competitors raise theirs, probably because the price movements are interpreted as signal of market saturation. Pitfield analyses the price behaviours of low-cost carriers competing on UK-based markets, and finds evidence of correlation between the fares. He also suggests that the temporal pricing discrimination adopted by duopolistic low-cost markets is a threat to the recovery of all fixed costs. Piga and Bachis [24] find a positive correlation between a LCC's market share at the origin airport and the fares it offers. Analysing Ryanair's pricing strategy, Malighetti et al. [19, 25] find that competition induces a greater advance discount without significantly affecting the average fare offered. They also find that Ryanair, after stimulating new demand and increasing the frequency of its existing flights, has consolidated its dominant position by employing a less aggressive pricing strategy.

To the best of our knowledge, this is the first work that explicitly aims to empirically measure the fare response of low-cost carriers. As noted by Barbot [26], the literature lacks theoretical and empirical research on the strategic behaviours of low-cost carriers. Barbot develops a two-stage game with horizontal and vertical differentiation in order to model when a low-cost incumbent is more willing to deter or accommodate a new entry. She found that LCCs may be successful in keeping out other LCCs, but fail when the rival is an FSC.

\section{Data}

Our work is based on a joint analysis of the OAG scheduling databases and a collection of web fares published by easyJet. We collected all fares from the easyJet booking website on every day during the period September 2006September 2009. These data therefore account for daily price variation, but not intraday changes. For each flight, we begin checking the price 90 days prior to departure and continue until the day before departure. The fares considered in this paper include basic tariffs, airport charges, and other taxes and unavoidable costs. They exclude supplements such as speedy boarding, voluntary carbon tax, extra baggage, and special insurance.
We select new entries based on the OAG databases. There were about 200 entries on routes (400 one-way) where easyJet was incumbent. Of those, in some cases the newcomers remain for very short periods. We therefore only consider entries where the new carrier served the route for at least 2 months. Similarly, we only take into account cases where easyJet served the route for at least 2 months before and 2 months after the new entry. In order to avoid peak demand effects, we also exclude all entries that happened within 2 weeks of Easter, Christmas and all other bank holidays. These criteria reduce the number of new entries in our sample to 97 (194 one-way). Thirty-nine of these were previously an easyJet monopoly; there was already competition on the remaining 58 .

Figure 2 reports the temporal distribution of entries detected on all easyJet routes and of the subset where easyJet had a monopoly. The major peaks are in 2006 and 2007. The slowdown of this process in 2008 and 2009 is probably related to the effects of the economic crisis on the European airline industry.

Figure 3 shows the geographical distribution of easyJet routes affected by new competitors. The vast majority involve either the UK, airports in southern Spain, or the Italian market.

Table 2 ranks the competitors by the number of entries, and also reports the share of entries by carrier type. Most of the entries were by low-cost and scheduled charter carriers. Although Ryanair and easyJet have different business models and target different markets (with preferences for secondary and primary airports respectively), it was Ryanair that most frequently competed for easyJet routes with 18 new one-way entries. The networks of the two main European LLCs are still expanding, however, and more overlapping may be unavoidable in the future. Another major source of competition comes from airlines like Thomsonfly and First Choice, which could be defined as low-cost or scheduled charters.

One-third of the new entries were by FSCs, signaling that even a LCC incumbent may be frequently challenged by FSCs. One good example is the new service started by Lufthansa Italia in 2009 from Malpensa, which was already an easyJet base.

\section{Methodology}

LCCs have shown great agility in adapting their prices to fluctuations in demand [27]. We therefore believe that if a LCC fare response to entry exists, the greater part will take place in a short time window. We focus on the short-term reactions of easyJet by examining the fare structures of comparable flights in a seven-day time window before and after the entry events. We are 
Fig. 2 Temporal distribution of one-way entries on easyJet routes

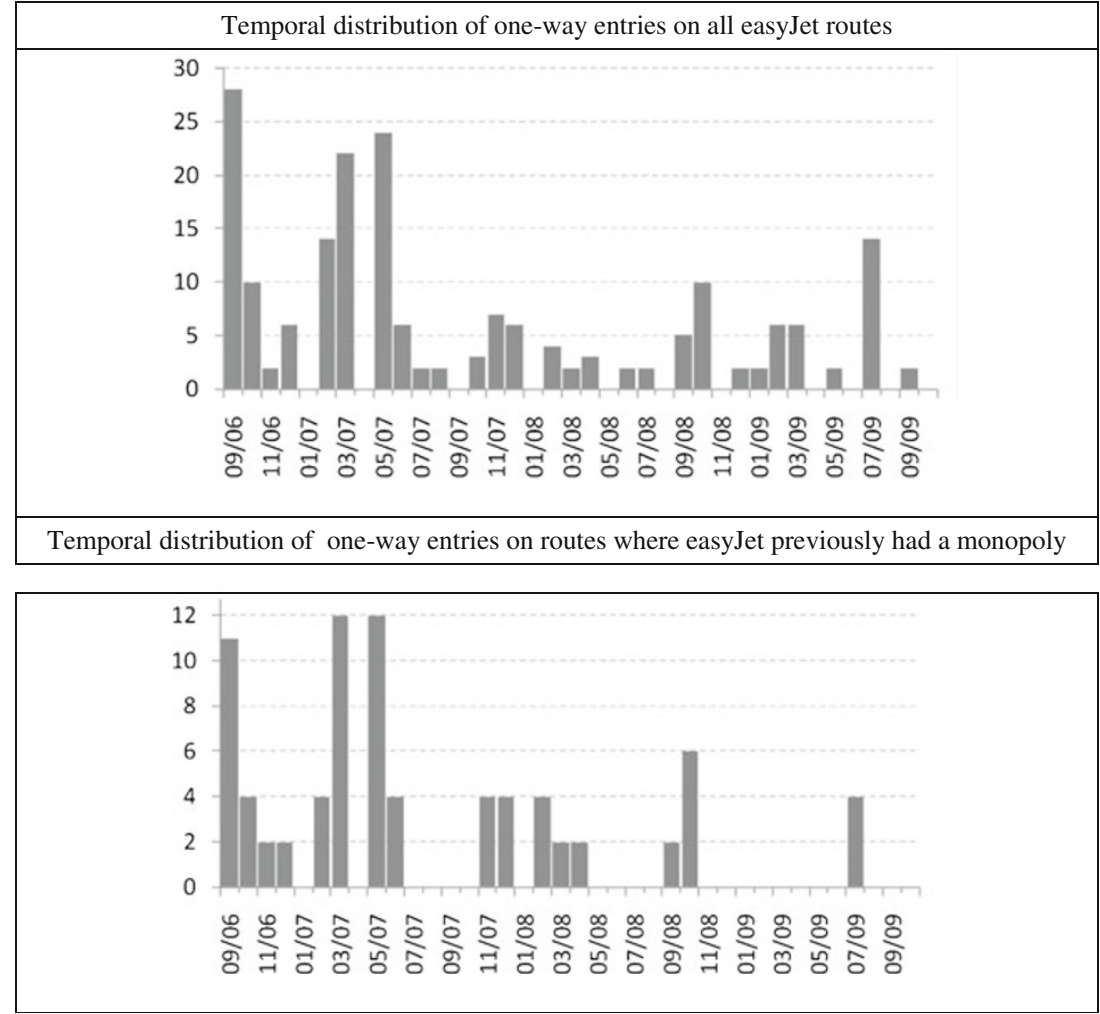

interested in three aspects of pricing: the average fare, easyJet's ability to exploit demand by discriminating between passengers with different booking times, and the magnitude of the fare dispersion.

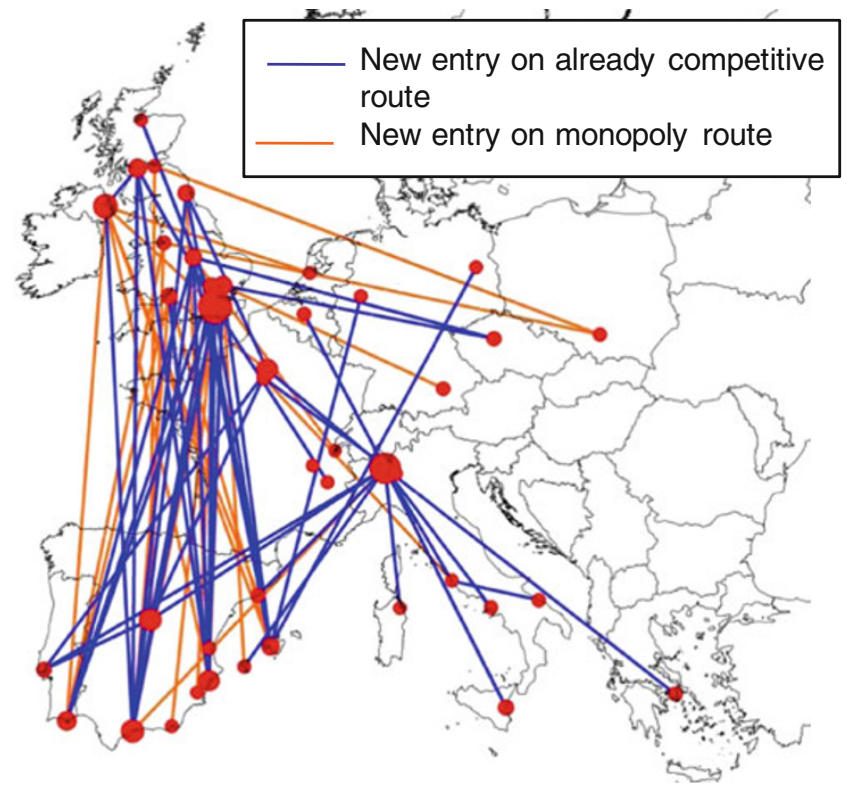

Fig. 3 Geographical distribution of easyJet routes challenged by new competitors
As pointed out by Gorin and Belobaba [28], when revenue management and dynamic pricing are at work, an analysis restricted to average fares may misinterpret the predatory behaviours of airlines. Further, as suggested by Martin and Koo [12], we want to emphasize the dynamic nature of fares by looking at their day-to-day variation.

The third variable, price dispersion, is more controversial in the literature and bears elaboration. Several definitions have been employed: the range between the maximum and minimum fares [29], the coefficient of variation [30], and the power divergence statistic [12]. The power divergence statistic (PDS) accounts for timedependent pricing and measures the similarity of price distributions in different airfare histories. Thus, if a carrier applies different temporal fare curves for different flights, their PDS will increase. We want to separate this kind of behaviour from price adjustments "unplanned" related to greater demand uncertainty and other strategic interactions. Thus, we shall depart from previous works by decomposing the price volatility into two effects: one connected to variations of the predicted temporal fare curve, and the other to daily price adjustments around the predicted curve.

We employ the two-step methodology developed in Malighetti et al. [19-25]. Firstly, for each flight, we calculate the average price $\mathrm{P}$ over the 90 days prior to departure. 
Table 2 Top new entrants on easyJet routes and the shares of entries generated by carriers with different business models

\begin{tabular}{llll}
\hline Carrier & $\begin{array}{l}\text { No. of one-way } \\
\text { entries detected }\end{array}$ & Carrier type & $\begin{array}{c}\% \text { of new } \\
\text { entries }\end{array}$ \\
\hline Ryanair & 18 & $\begin{array}{c}\text { Low cost/Charter } \\
\text { scheduled } \\
\text { Network }\end{array}$ & $66 \%$ \\
Thomsonfly & 16 & Regional & $2 \%$ \\
First Choice & 16 & & \\
Volare & 8 & & \\
Lufthansa & 6 & & \\
Aer Lingus & 4 & & \\
\hline
\end{tabular}

The dynamic pricing coefficient $\beta$ is determined by fitting the following function:

$\mathrm{p}_{\mathrm{i}}=\frac{1}{\alpha \cdot(1+\beta \cdot \mathrm{i})}$

where $\mathrm{i}$ is the number of days between reservation and departure and $p_{i}$ is the price offered on that date. A small $\beta$ means that the price decreases slowly as advance booking increases. A large $\beta$ indicates that advance purchases benefit from a significant discount. . For example, if $\beta$ is 0.1 , buying the ticket 90 days in advance, yields a $90 \%$ discount on the maximum fares. The form of the price function is a hyperbola with the price going up as the flight date approaches. Such as function belongs to the curve families that are coherent with Low cost carriers' pricing strategy optimization as described by Anjos [20]. After $\beta$ has been estimated we compute a dispersion index (D) for the flight, the sum of squared errors between $p_{i}$ and its prediction based on Eq. 1.

Secondly, we compare flights offered during the 7 days after entry of a new carrier to similar flights in the 7-day window prior to the entry. It is well known that flights sharing the same departure and arrival airports but having different departure times or days of the week sometimes exhibit very different pricing strategies. Therefore, in order to be matched, two flights must be on the same route, occur on the same day of the week, and have departure times within $30 \mathrm{~min}$ of each other. This constraint ensures that variations observed in the pricing structure are not influenced by demand fluctuations due to the hour and weekday of departure. We preferred to employ a short matching time frame since testing greater time window like $1 \mathrm{~h}$ we fund only $3 \%$ more of potentially linked pair but with some potential multiple matching on about 20 route with daily frequency higher than 5 flight a day.

Further, to negate the influence of peak demand days, we exclude all entries that took place within two weeks of Easter, Christmas, and bank holidays as mentioned in the previous section. Among the remaining data we were able to match 1,809 "linked pairs" of flights.

For each linked pair we calculate the difference in $\mathrm{P}$, $\beta$ and $\mathrm{D}$. Accordingly, the notation $\Delta \mathrm{P}_{\mathrm{i}, \mathrm{t} \rightarrow \mathrm{t}-7}$ refers to the difference between the average price of the $i^{\text {th }}$ observation (defined by the triplet of departure airport, arrival airport, and departure time) departing $\mathrm{t}$ days after an entry and the average price of the matched observation departing 7 days earlier (see Fig. 4). Note that our constraints on the sample require that the time difference between a linked pair is always exactly 7 days. The same convention is used for variations in beta and overall price dispersion (D).

After computing the differences described above, the first step is to check if they are statistically different from zero. If so, we may conclude that the entry affected the pricing structure of easyJet. This analysis has been conducted on the flight level and on the route level. Next we determine which variables affect the fare response by building up a panel of observations for each delta $(\Delta \mathrm{P}, \Delta \beta$ and $\Delta \mathrm{D}$ ) with length equal to the time window (7 days). Our 194 entries and 1,809 linked pairs, grouped by the triplet of departure airport, arrival airport and departure time, result in 322 delta observations with an average panel length of 5.6.

Our explanatory variables assess market conditions before the new entry $(\mathrm{Y})$ and their variations pre- and postentry $(\Delta \mathrm{X})$

$\Delta \mathrm{P}_{\mathrm{i}, \mathrm{t} \rightarrow \mathrm{t}-7}=\alpha \Delta \mathbf{X}_{\mathrm{i}, \mathrm{t} \rightarrow \mathrm{t}-7}+\alpha_{1} \mathbf{Y}_{\mathrm{i}, \mathrm{t}}+\varepsilon_{\mathrm{i}, \mathrm{t}}$

$\Delta \beta_{\mathrm{i}, \mathrm{t} \rightarrow \mathrm{t}-7}=\alpha^{\prime} \Delta \mathbf{X}_{\mathrm{i}, \mathrm{t} \rightarrow \mathrm{t}-7}+\alpha_{1}^{\prime} \mathbf{Y}_{\mathrm{i}, \mathrm{t}-7}+\varepsilon_{\mathrm{i}, \mathrm{t}}^{\prime}$

$\Delta \mathrm{D}_{\mathrm{i}, \mathrm{t} \rightarrow \mathrm{t}-7}=\alpha^{\prime \prime} \Delta \mathbf{X}_{\mathrm{i}, \mathrm{t} \rightarrow \mathrm{t}-7}+\alpha_{1}^{\prime \prime} \mathbf{Y}_{\mathrm{i}, \mathrm{t}-7}+\varepsilon_{\mathrm{i}, \mathrm{t}}^{\prime \prime}$

In detail, we consider the following explanatory variables:

- The values of the variables before entry (P, $\beta$ and $\mathrm{D}$ at $\mathrm{t}-7)$

New carrier entrer on routes where easyJet is incumbent time window before new entry $\quad$ time window after new entry
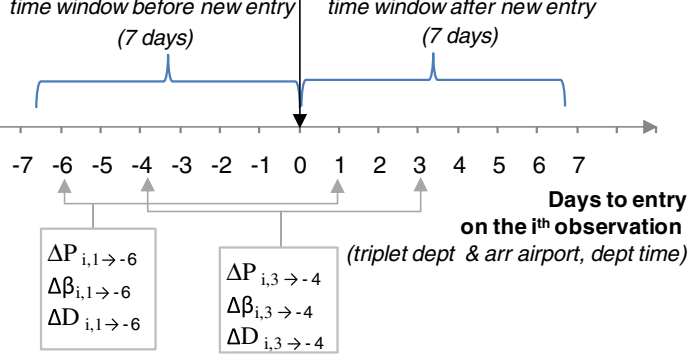

Fig. 4 Time windows pre and post entry and related variations 
- $\quad$ _no competitor, a dummy for routes where easyJet was a monopolist

- $t$, the time

- D H Dep Closer, a dummy variable equal to one if the service offered by a new entrant has a departure time closer to the easyJet departure time compared to other existing flights

- H Dep closeness, the time span between the easyJet flight and the closest flight

- U2 seats $t-7$, daily seats offered on the route by easyJet

- $\Delta$ seats FCSs, overall increase in the daily seats provided by a FCS competitor after its new entry

- $\Delta$ seats LCCs Comp, overall increase in the daily seats provided by a LCC competitor after its new entry

- D_hub, a dummy for domestic routes departing or arriving at a major European hub (one of the 10 biggest European airports)

Table 3 reports summary statistics for the explanatory variables. The correlation matrix of independent variables is provided in Appendix B.

In the following sections, we will discuss the estimated models for $\mathrm{P}, \beta$ and $\mathrm{D}$.

\section{Results}

Appendix A reports the box plots of $\mathrm{P}, \beta$ and $\mathrm{D}$ for each day in the time window before and after the entry event. Table 4 shows summary statistics regarding the significance of variations in the price structure between matched flights. We report statistics aggregated at the route and observation levels as well as statistics for the price structures of each linked pair.

We find that the intensity $\beta$ of dynamic pricing decreased after a new entry. The effect is statistically significant at all aggregation levels. This result may reflect a decreased capacity on the part of carriers to exploit differences in the "willingness to pay" of customers with different advance booking times. Such an interpretation would be in line with

Table 3 Summary statistics of the independent variables

\begin{tabular}{lllll}
\hline Each matched flight & Mean & St. dev. & Min & Max \\
\hline D_no competitor & 0.38 & 0.48 & 0 & 1 \\
D_H Dep Closer & 0.05 & 0.22 & 0 & 1 \\
H Dep closeness & 0.40 & 0.22 & 0.003 & 0.986 \\
U2 seats t-7 & 355 & 209 & 149 & 936 \\
$\Delta$ seats LCCs Comp & 46.18 & 98.62 & -268 & 470 \\
$\Delta$ seats FCSs & 46.92 & 109.92 & -175 & 743 \\
D_hub & 0.61 & 0.49 & 0 & 1 \\
\hline
\end{tabular}

the idea that dynamic pricing is a way of implementing price discrimination among customers with different elasticities, and thus $\beta$ tends to fall as competition increases.

We also find a decrease of about 2.6-2.8 $€$ (about 3 $4 \%$ ) in the average fare offered over the 90 days before departure. The sign and magnitude of the effect are the same at all aggregation levels, but lose significance at the route level. This result suggests that easyJet's response is more marked on routes served with higher frequency. This explanation is confirmed by the panel data analysis described below.

We find no evidence of changes in the dispersion of daily prices around the predicted temporal fare curve.

These variations in the average price, beta and dispersion might also be related to specific changes in the competitive structure of the routes, as represented by the explanatory variables defined in the previous section. In the next sections, we investigate the source of variations in the easyJet fare response by applying panel data analysis.

\subsection{Average price}

In Table 5 we see that the average price reduction is stronger on routes where competition was not present before the new entry. Ceteris paribus, this effect induces an average reduction of $7.9 €$. (The magnitude of the reaction depends on the average price applied before the new entry.) We also find evidence of a time trend in the average fare applied. As expected, if the departure time of the new entry is close to that of the easyJet flight, the fare reduction is greater. The reaction also tends to be stronger on routes that are more densely served by easyJet.

Our data do not show evidence that easyJet reacts strongly when the new entry is a low-cost carrier. However, we find a significant reaction when a FCS enters the route. Two interpretations are possible. On the one hand, given easyJet's vision of "value for money", perhaps the customers targeted by easyJet are more similar to the customers targeted by traditional carriers than to those of other lowcost carriers. On the other hand, perhaps easyJet reacted to FCSs entries by increasing its differentiation from the FCS model.

Finally, we find a stronger reduction in the average price on routes connected to a hub airport. This effect is challenging to interpret, since easyJet applies a point-to-point service with no network externalities. Nevertheless, we point out that this dummy maintains its sign and significance under a number of different specifications, such as models that include variables relating to the GDP and population of served areas. ${ }^{2}$ We offer two possible explanations. In the

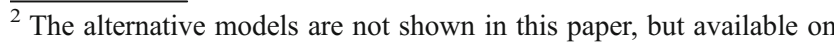
request.
} 
Table 4 Statistical significance of variations ( $t$-test) in the price structure of matched flights before and after the entry event

\begin{tabular}{|c|c|c|c|c|}
\hline Level of aggregation & No. deltas & Avg. value prior to entries $(t=-7 \ldots-1)$ & Mean $\Delta \mathrm{t} \rightarrow \mathrm{t}-7$ & $\mathrm{P}$ value \\
\hline \multicolumn{5}{|l|}{ Each matched flight } \\
\hline$P_{i, t}$ & 1809 & 68.27 & $-2.892 * * *$ & 0.000 \\
\hline$\beta_{\mathrm{i}, \mathrm{t}}$ & 1809 & 0.045 & $-0.0087 * * *$ & 0.001 \\
\hline $\mathrm{D}_{\mathrm{i}, \mathrm{t}}$ & 1809 & 0.221 & 0.0001 & 0.998 \\
\hline \multicolumn{5}{|c|}{ Aggregated by observation (dept,arr,dept time) } \\
\hline $\mathrm{P}_{\mathrm{i}}$ & 322 & 68.38 & $-2.529 *$ & 0.063 \\
\hline$\beta_{\mathrm{i}}$ & 322 & 0.045 & $-0.0089 * * *$ & 0.000 \\
\hline $\mathrm{D}_{\mathrm{i}}$ & 322 & 0.228 & 0.0022 & 0.834 \\
\hline \multicolumn{5}{|c|}{ Aggregated by route (dept,arr) } \\
\hline $\mathrm{P}$ & 194 & 76.51 & -2.610 & 0.171 \\
\hline$\beta$ & 194 & 0.035 & $-0.006^{* * *}$ & 0.001 \\
\hline $\mathrm{D}$ & 194 & 0.258 & -0.015 & 0.254 \\
\hline
\end{tabular}

case of a FCS entry, since these routes are particularly important for the economy of a hub-and-spoke network carrier, there is a good chance that the newcomer will apply predatory price increases and cause easyJet to react more strongly. In the case of a LCC entry, the scarce presence of low-cost service in hubs is an important source of differentiation for easyJet, again inducing the carrier to react forcefully.

\subsection{Dynamic pricing}

The intensity of the dynamic pricing applied by easyJet, captured by the $\Delta \beta$ parameter, significantly decreases after a new entry. As is the case with average fares, the effect is greater on routes where easyJet was a monopolist (see Table 6). When the newcomer is a traditional carrier, we find a larger and statistically more significant decrease of dynamic pricing intensity after entry, proportionally to the

Table 5 Determinants of the average price reaction

\begin{tabular}{lll}
\hline$\Delta \mathrm{P}$ & Coefficient & P value \\
\hline P t-7 & $-0.4244^{* * *}$ & 0.000 \\
D_no competitor & $-8.5427 * * *$ & 0.000 \\
t & $-0.6233^{* *}$ & 0.029 \\
D_H Dep Closer & $-5.5647 *$ & 0.058 \\
H Dep closeness & 4.5155 & 0.298 \\
U2 seats t-7 & $-0.0223 * * *$ & 0.000 \\
$\Delta$ seats LCCs Comp & -0.0049 & 0.950 \\
$\Delta$ seats FCSs & $-0.0237 * * *$ & 0.007 \\
D_hub & $-9.1777 * * *$ & 0.000 \\
const & $44.4667 * * *$ & 0.000 \\
R-squared within 0.22 & & \\
between 0.29 & & \\
overall 0.24 & & \\
\hline
\end{tabular}

number of new offered seats. Recall that a smaller value of beta means that the airline is less able to exploit temporal price discrimination. This result therefore supports the idea that FCSs typically employ less aggressive dynamic pricing strategies, targeting the upper tail of less price-sensitive consumers. As a consequence, easyJet's market power decreases in this demographic. easyJet may therefore be led to differentiate its pricing behaviour only for these "last booking" and "less price-sensitive" customers, for example by maintaining discounted fares at pre-entry levels while reducing fares offered on the last booking day. This strategy would indeed lead to smaller values of beta. In contrast, a LCC entering the route with a similar dynamic pricing strategy will have a more homogeneous impact on easyJet's demand.

Routes to or from hub airports have significantly higher values of $\Delta \beta$. In accordance with our previous discussion of average prices, this easyJet reaction appears more aggressive.

\subsection{Price dispersion}

One of the novelties of our approach is the decomposition of price dispersion into two components. The first is related to dynamic pricing activity, and the second captures unexpected day-to-day price adjustments. Since the capacity and frequency of scheduled services are fixed in advance, price is the main variable involved in short-term adjustments. Therefore, we interpret larger price dispersions as reflecting a greater level of demand uncertainty and also as the outcome of a short-term strategic interaction engaged by the carriers.

The aggregate analysis of dispersion shown in Table 4 does not report significant variations after new entries. However, the panel analysis of Table 7 shows some interesting significant relations. Firstly, dispersion tends to increase on routes where easyJet was a monopolist, in line with expectations. Secondly, we find that the dispersion is 
Table 6 Determinants of variations in the dynamic pricing intensity $\Delta \beta$

\begin{tabular}{lll}
\hline$\Delta \beta$ & Coefficient & P value \\
\hline$\beta$ t-7 & $-0.714040^{* * *}$ & 0.000 \\
D_no competitor & $-0.00947^{* * *}$ & 0.007 \\
$\mathrm{t}$ & 0.000169 & 0.766 \\
D_H Dep closer & 0.001429 & 0.801 \\
H Dep closeness & 0.007598 & 0.296 \\
U2 seats t-7 & 0.000011 & 0.185 \\
$\Delta$ seats LCCs Comp & -0.000007 & 0.617 \\
$\Delta$ seats FCSs & $-0.000039^{* *}$ & 0.010 \\
D_hub & $0.012822^{* * *}$ & 0.001 \\
const & $0.014061^{* * *}$ & 0.006 \\
R-squared within 0.51 & & \\
between 0.36 & & \\
overall 0.42 & & \\
\hline
\end{tabular}

significantly lower when a LCC enters the market than when the newcomer is a FCS. That could indicate, as argued above, that short-term strategic interactions are more important when easyJet is competing with traditional carriers. Another possible explanation is that the entry of a FCS with relatively stable pricing increases uncertainty for LCCs, since the former decreases the risk faced by passengers of not finding seats when booking close to the departure date. This alters the trade-off between waiting and risk, and could result in more potential customers adopting the waiting strategy. This effect would undermine easyJet's ability to separate markets by booking time.

\section{Conclusion and future developments}

As the low-cost presence increases and markets mature, we expect the number of low-cost incumbents on new routes to increase. This research pioneers the empirical study of low-cost carrier fare responses to new entries. Further, the study is interesting because it is applied to Europe, where public data on fares are not generally available and the low-cost phenomenon is relatively recent compared to the U.S. Because the strategies employed by low-cost carriers are extremely dynamic, we focus our attention on short-term fare reactions. Specifically, we applied an event-study approach within a time window of 7 days before and after each entry.

We analyze three components of easyJet's pricing strategies: i) the average fare offered, ii) the intensity of dynamic pricing, and iii) the dispersion of day-to-day price adjustments around the predicted temporal fare curve. The last measure is a novel addition to the usual methodology of this literature.
Table 7 Determinants of variations in price dispersion, $\Delta$ Dispersion

\begin{tabular}{lll}
\hline$\Delta$ Dispersion & Coefficient & P value \\
\hline Dispersion t-7 & $-0.87546^{* * *}$ & 0.000 \\
D_no competitor & $0.05785^{* * *}$ & 0.003 \\
$\mathrm{t}$ & -0.00335 & 0.263 \\
D_time Comp Closer & $0.04918^{*}$ & 0.094 \\
H Dep closeness & -0.06035 & 0.118 \\
U2 seats t-7 & 0.00005 & 0.172 \\
$\Delta$ seats LCCs Comp & $-0.00017^{* *}$ & 0.010 \\
$\Delta$ seats FCSs & $0.00017^{* *}$ & 0.040 \\
D_hub & $-0.03718^{*}$ & 0.066 \\
const & $0.19086^{* * *}$ & 0.000 \\
$R$-squared within 0.46 & & \\
between 0.23 & & \\
overall 0.38 & & \\
\hline
\end{tabular}

We find evidence that easyJet's average prices decreased by about $3 \%$ after a new entry. The reaction tends to be stronger on routes that are more densely served by easyJet. The intensity of dynamic pricing tends to decrease after a new entry. A natural explanation for this effect is that competition reduces the ability of LCCs to apply temporal discrimination of passengers. These results are in line with Gerardi and Shapiro's (2009) predictions on price dispersion. We find little evidence that day-to-day adjustments are more widely dispersed around the predicted price curve, especially on routes where easyJet was a monopolist. By decomposing price dispersions into two factors, the dynamic pricing intensity and dispersion, we can reconcile our empirical findings with both of the main theories on price dispersion.

We also find evidence that FCSs provoke a stronger reaction than LCCs, a counterintuitive result. One possible explanation may be that in some respects, the quality of easyJet's services is perceived to be closer to that of FCSs than to that of LCCs. However, we believe that the pricing strategy pursued by FCSs greatly undermines the ability of LCCs to employ inter-temporal price discrimination. This theory is confirmed by the day-to-day adjustments, which exhibit a higher volatility in response to a FCSs entrant. Finally, our work suggests that LCCs have a more aggressive reaction on routes involving Hub airports.

The main limitation of our work is that we do not consider the pricing structure and average fares applied by the new entrants. Furthermore, we limited this analysis to shortterm reactions and competition on exactly the same route. New entries on alternative or adjacent routes could also induce fare responses. However, all these issues are left to future research. 


\section{Appendix A}

Box plot of average price, dynamic pricing intensity and price dispersion

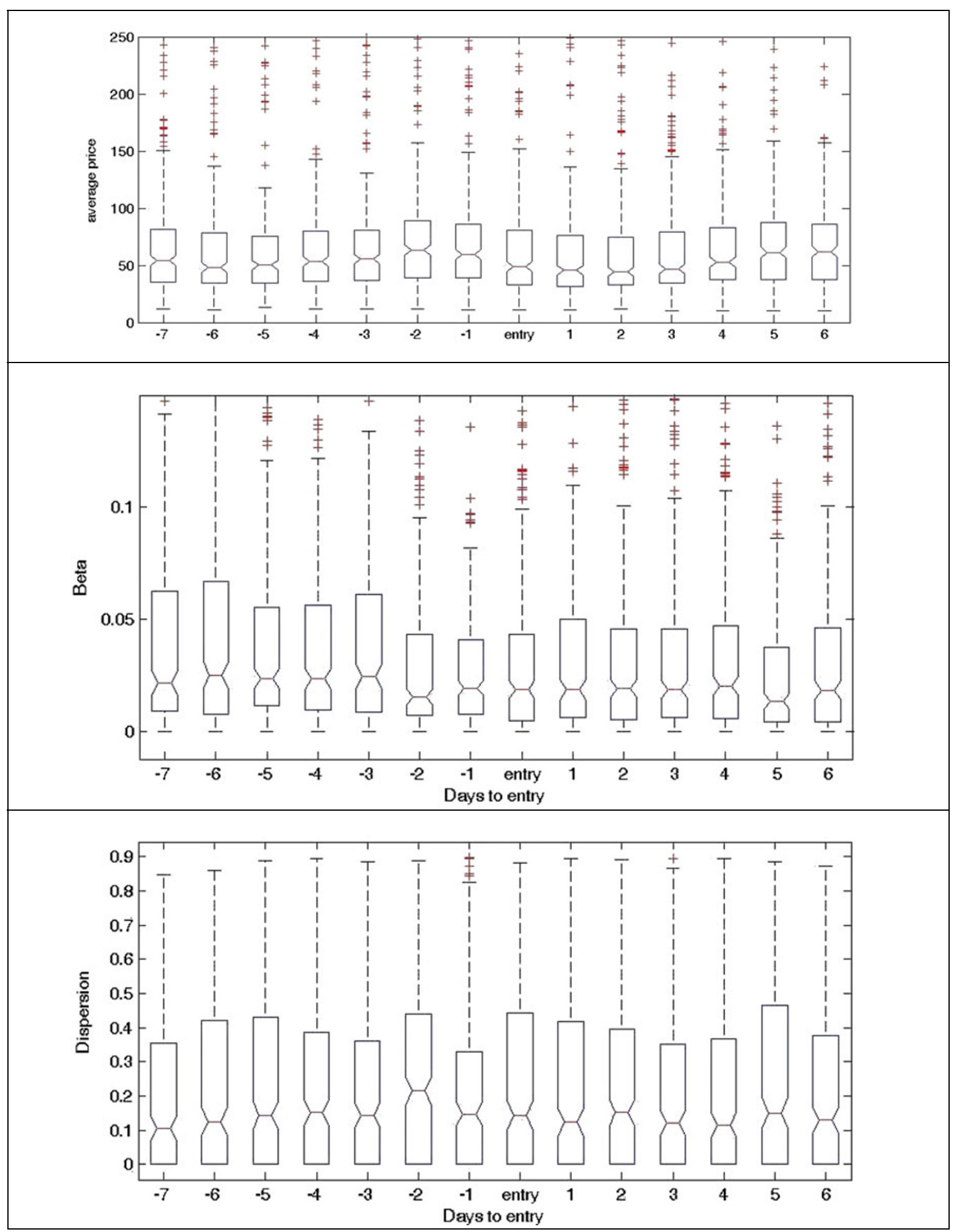




\section{Appendix B}

Table 8 Independent variable Correlation matrix

\begin{tabular}{|c|c|c|c|c|c|c|c|c|}
\hline & $\begin{array}{l}\text { D_no } \\
\text { competit }\end{array}$ & $\mathrm{t}$ trend & $\begin{array}{l}\text { D_H Dep } \\
\text { closer }\end{array}$ & $\begin{array}{l}\text { H Dep } \\
\text { closeness }\end{array}$ & U2 seats $\mathrm{t}-7$ & $\begin{array}{l}\Delta \text { seats LCCs } \\
\text { Comp }\end{array}$ & $\begin{array}{l}\Delta \text { seats } \\
\text { FCSs }\end{array}$ & D_hub \\
\hline D_no competitor & 1 & & & & & & & \\
\hline$t$ trend & 0.0622 & 1 & & & & & & \\
\hline D_H Dep closer & -0.1839 & -0.0747 & 1 & & & & & \\
\hline H Dep closeness & 0.2884 & 0.0636 & 0.0129 & 1 & & & & \\
\hline$U 2$ seats $t-7$ & -0.0706 & -0.0652 & 0.0284 & 0.0802 & 1 & & & \\
\hline$\triangle$ seats $L C C s$ & 0.1643 & -0.1494 & 0.1215 & -0.1613 & -0.0733 & 1 & & \\
\hline$\triangle$ seats FCSs & -0.2197 & -0.1014 & 0.0508 & -0.0941 & 0.2086 & -0.2062 & 1 & \\
\hline D_hub & -0.3539 & -0.0444 & 0.0496 & -0.1027 & 0.3198 & -0.0608 & 0.3235 & 1 \\
\hline
\end{tabular}

Open Access This article is distributed under the terms of the Creative Commons Attribution License which permits any use, distribution, and reproduction in any medium, provided the original author(s) and the source are credited.

\section{References}

1. Mason KJ, Alamdari F (2007) EU network carriers, low cost carriers and consumer behaviour: a Delphi study of future trends. J Air Transport Manag 13(5):299-310

2. Windle R, Dresner M (1999) Competitive responses to low cost carrier entry. Transport Res E 35:59-75

3. Windle R, Dresner M (1995) The short and long run effects of entry on US domestic air routes. Transp J 35(2):14-25

4. Ito H, Lee D (2003) Incumbent responses to lower cost entry: evidence from the US airline industry. Working Paper 2003-12, Brown University Department of Economics, Providence, US

5. Forsyth P (2003) Low cost carriers in Australia: experiences and impacts. J Air Transport Manag 9(5):277-284

6. Alderighi M, Cento A, Nijkamp P, Rietveld P (2004) The entry of low cost Airlines, Timberg Institute Discussion Paper, TI 2004$074 / 3$

7. Morrison S, Winston C (1995) The evolution of the airline industry. The Brookings Institution, Washington DC

8. Goolsbee A, Syverson C (2008) How do incumbents respond to the threat of entry? Evidence from the major airlines full access. Q J Econ 123(4):1611-1633

9. Daraban B, Fournier GM (2008) Incumbent responses to low-cost airline entry and exit: a spatial autoregressive panel data analysis. Res Transp Econ 24:15-24

10. Borenstein S, Rose N (1994) Competition and price dispersion in the U.S. Airline industry. J Polit Econ 102(4):653-683

11. Gerardi K, Shapiro AH (2009) Does competition reduce price discrimination? New evidence from the airline industry. J Polit Econ 117(2):1-37

12. Mantin B, Koo B (2009) Dynamic price dispersion in airline markets. Transport Res E 45(2009):1020-1029

13. Dana J (1999) Equilibrium price dispersion under demand uncertainty: the roles of costly capacity and market structure. Rand J Econ 30(4):632-660
14. McGill JI, Van Ryzin GJ (1999) Revenue management: research overview and prospects. Transp Sci 33:233-256

15. Talluri KT, Van Ryzin GJ (2004) The theory and practice of revenue management. Kluwer Academic Publishers, Norwell, MA

16. McAfee PR, te Velde V (2006) Dynamic Pricing in the Airline Industry. In: Hendershott TJ (ed) Handbook on Economics and Information Systems, Elsevier

17. Button K, Vega H (2007) The uses of the "temporal-fares-offered curve" in air transportation. Working Paper, George Mason University

18. Koenigsberg O, Muller E, Vilcassim NJ (2008) easyJet ${ }^{\circledR}$ pricing strategy: should low-fare airlines offer last-minute deals? Quant Mark Econ 6:279-297

19. Malighetti P, Paleari S, Redondi R (2009) Pricing strategies of lowcosts airlines: the Ryanair case. J Air Transport Manag 15(4):195-203

20. Anjos M, Cheng R, Currie C (2005) Optimal pricing policies for perishable products. Eur J Oper Res 166(1):246-254

21. Piga CA, Bachis E (2007) Pricing Strategies by European Traditional and Low-Cost Airlines: or, When Is It The Best Time To Book On Line?' In: Darin Lee (ed) Advances in Airline Economics, Volume 2: The Economics of Airline Institutions, Operations and Marketing. Elsevier

22. Pels E, Rietveld P (2004) Airline pricing behaviour in the LondonParis market. J Air Transport Manag 10:279-283

23. Pitfield DE (2005) A time series analysis of the pricing behaviour of directly competitive 'low-cost' airlines. Int J Transport Econ 32:15-38

24. Piga CA, Bachis E (2006) Hub Premium, Airport Dominance and Market Power in the European Airline Industry. Rivista di Politica Economica. Sept-Oct 2006, 11-54

25. Malighetti P, Paleari S, Redondi R (2010) Has Ryanair's pricing strategy changed over time? An empirical analysis of its 20062007 flights? Tour Manag 31:36-44

26. Barbot C (2009) Can low cost carriers deter or accommodate entry? Transport Res E 44:883-893

27. ICCSAI (2008) Chapter 6. Air Transport in Europe: ICCSAI Fact Book 2008BookSurge Publishing, p. 1-250, ISBN: 9781439209493 (edited by Malighetti P., Paleari S., Redondi R.)

28. Gorin T, Belobaba P (2008) Assessing predation in airline markets with low-fare competition. Transport Res Part A 42:784-798

29. Brynjolfsson E, Smith MD (2000) Frictionless commerce: a comparison of internet and conventional retailers. Manag Sci 46(4):563-585

30. Sorensen AT (2000) Empirical price dispersion in retail markets for prescription drugs. J Polit Econ 108:833-850 